\title{
Experimental Studies on Heat Transfer Analysis of A Mild Steel Using Jet Impingement Cooling Technique
}

\author{
Mohammed Asif Kattimani ${ }^{1}$, Mohammad Abbas Khan ${ }^{2}$, Mohd Ishaq ${ }^{2}$, Mohammed Asad $^{3}$ \\ Department of mechanical engineering LIET-Hyd. ${ }^{1,2}$, Asst.professor, ${ }^{1,2}$ \\ Department of mechanical engineering LIET-Hyd. ${ }^{3,4}$ Research scholar ${ }^{3,4}$ \\ Email:md.asifkattimani@lords.ac.in ${ }^{1}$, mdishaq110@gmail.com ${ }^{3}$
}

\begin{abstract}
The objective of this study is a systematic experimental analysis of a cooling process of a hot stagnant mild steel plate of 1 meter square plate and $20 \mathrm{~mm}$ thickness by impinging circular water jets. The effect of the water temperature and the flow rate were analyzed. The temperature history of the plate during the cooling process was measured with thermocouples within the plate \& the different parameters that were considered during analysis are Nozzle to plate distance, nozzle gaps, different flow rates, and nozzle diameter during impingement of water jets on hot steel rolled plates. The effect of spray height on cooling was minor within the experimental conditions. The water temperature has negligible effect on the heat extraction within the experimental conditions of this study. The stationary plate has a significant effect on the heat fluxes and also the amount of energy extracted from the plat.
\end{abstract}

Index Terms- $\quad$ Mild steel, Thermocouples, Temperature Indicator, Nozzles, Stand, Pipe \& Blower.

\section{INTRODUCTION}

Jet impingement cooling is one of the main heat transfer enhancement techniques due to its capabilities of producing high convective heat transfer rates. Impinging jet has been employed and widely used for the heat transfer augmentation such as

1. Cooling of hot steel plates

2. Tempering of glass

3. Drying of papers and films

4. Cooling of turbine blades and electronic components.

Functionally graded materials (FGMs) are composite materials where the composition or the microstructure is locally varied so that a certain variation of the local material properties is achieved.

A functionally graded material (FGM) is a twocomponent composite characterized by a compositional gradient from one component to the other. In contrast, traditional composites are homogeneous mixtures, and they therefore involve a compromise between the desirable properties of the component materials. Since significant proportions of an FGM contain the pure form of each component, the need for compromise is eliminated. The properties of both components can be fully utilized.

\subsection{Introductions of changes in cooling mechanism}

One of the important parameters affecting jet impingement heat transfer is the flow condition at the nozzle exit. The swirl flow at the nozzle would alter the jet spreading rate flow entrainment and tuber balance characteristics before its impingement on the Surface. It is important to understand the swirling effect on flows and heat transfer so that distinction between favorable and undesirable effects of swirl to many flow and heat transfer process could be made. Accelerated Cooling has been implemented in hot strip mill to reduce the duration of this process in order to coiling temperature and to obtain desirable grain structure. Temperature range for finishing (800- $\left.950{ }^{\circ} \mathrm{C}\right)$ and coiling $\left(510-750^{\circ} \mathrm{C}\right)$ For water the heat transfer coefficient is in the order of 5 to $100 \mathrm{kw} / \mathrm{m}-\mathrm{k}$ .The analysis consists of the measurement of Temperature in four aligned points inside the plate at the same depth one at the center line of impinging jet and the others at some regular distance.

1 Considerable studies have been conducted to optimize the flow characteristics for mild steel plate.

2 However, these studies are limited to study state conditions where the flow rate of impingement jet is constant with respect to time.

3 In this study, we consider both steady and pulsed jets.

\section{MATERIAL AND COMPONENTS}

\subsection{Steel metal plate (AISI304)}

Stainless steel types 304 and 304L. Type 304 is the most versatile and widely used stainless steel. It is also known as $18 / 8$ from the nominal composition of type 304 being $18 \%$ chromium and $8 \%$ nickel. It has excellent forming and welding characteristics. AISI 304 stainless can be deep drawn more severely than Types 301 and 302 without immediate heat softening, a characteristic that has made this grade dominant in the manufacture of drawn stainless steel parts such as sinks, splash backs and saucepans. Type 304 stainless steel also has outstanding welding characteristics. Post-weld annealing is not required to restore the excellent performance of this grade in a wide range of mildly corrosive conditions. Type 304L does not require post-weld annealing and finds extensive use in heavy gauge components where freedom from carbide welds precipitation is often required. 


\section{Available online at www.ijrat.org}

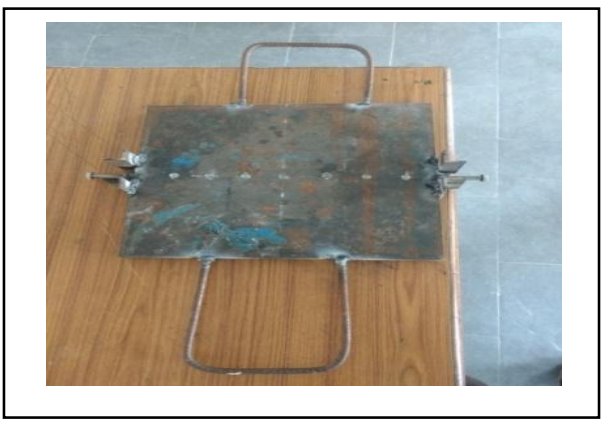

Fig.1.Steel metal plate Aisi304

\subsection{Thermocouples}

A Thermocouple is a sensor used to measure temperature. Thermocouples consist of two wire legs made from different metals. The wires legs are welded together at one end, creating a junction. This junction is where the temperature is measured. When the junction experiences a change in temperature, a voltage is created.

A thermocouple is an electrical device consisting two dissimilar electrical conductors forming electrical junctions at different temperatures. Six numbers of thermocouples are used to measure the temperature of heated square plate at different locations. Figure 2.2 shows K-type thermocouple used for temperature measurement.

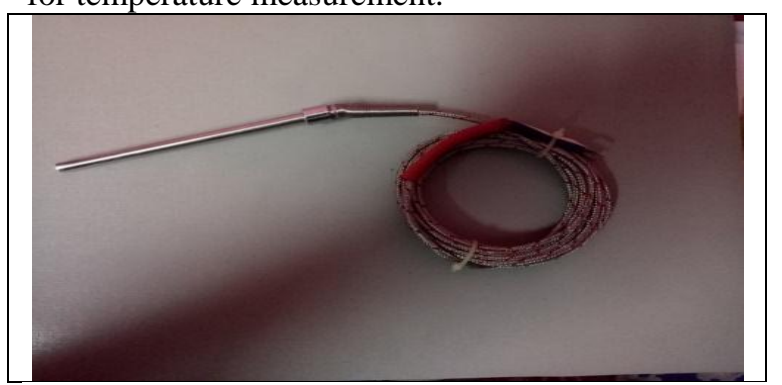

Fig.2.K-type thermocouple

\subsection{Temperature Display Panel}

A time Temperature Display Panelis a device or smart label that shows the accumulated timetemperature history of a product. Time temperature indicators are commonly used on food, pharmaceutical, and medical products to indicate exposure to excessive temperature (and time at temperature).

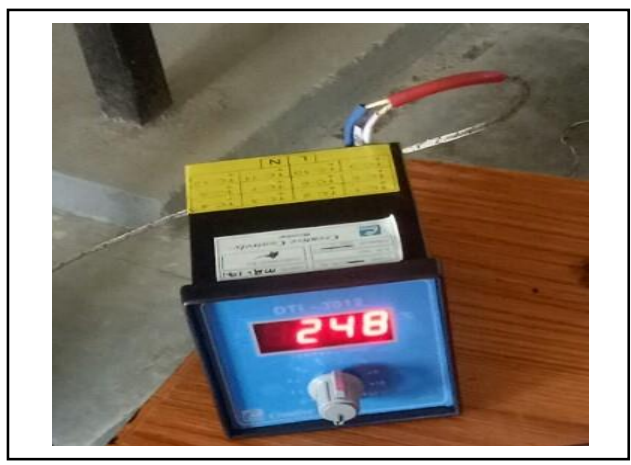

Fig.3.Temperature panel

\subsection{Nozzles}

A nozzle is often a pipe or tube of varying cross sectional area and it can be used to direct or modify the flow of a fluid. Four different types of nozzles were used with different lengths to flow of water at different height from square plate.

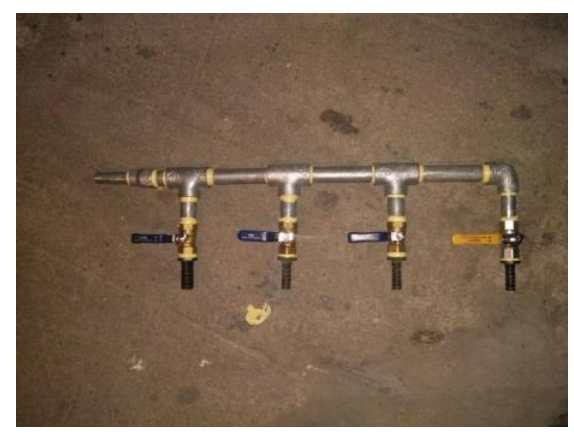

\subsection{Blower}

Fig.4.Types of Nozzles

A blower is an exhaust turbocharger. The exhaust handling system includes a dilution air filter and a blower to induce flow.

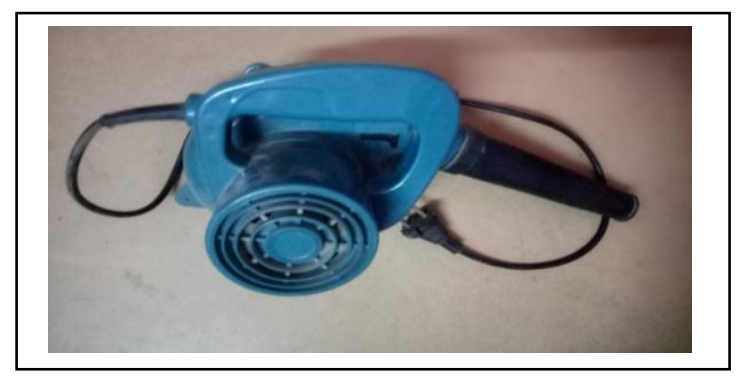

Fig.5. Blower

Sub-headings should be typeset in boldface and capitalize the first letter of the first word only. Section number to be in boldface roman.

\section{FABRICATION}

Fabrication is the building of metal structures by cutting, bending, and assembling processes. It is a value added process that involves the creation of machines, parts, and structures from various raw materials.

The measurement of heated plate temperature is carried out by holding the plate on a stand which is kept inside the tray. The plate is drilled with numbers of holes to hold thermocouples. The procedure followed for fabrication of following components is discussed below.

\subsection{Stand for holding plate}

A stand of height $5 \mathrm{ft}$ with width of $100 \mathrm{~cm}$ is fabricated using steel bars with standard welding procedure (arc welding) as shown in figure 8. 


\section{Available online at www.ijrat.org}

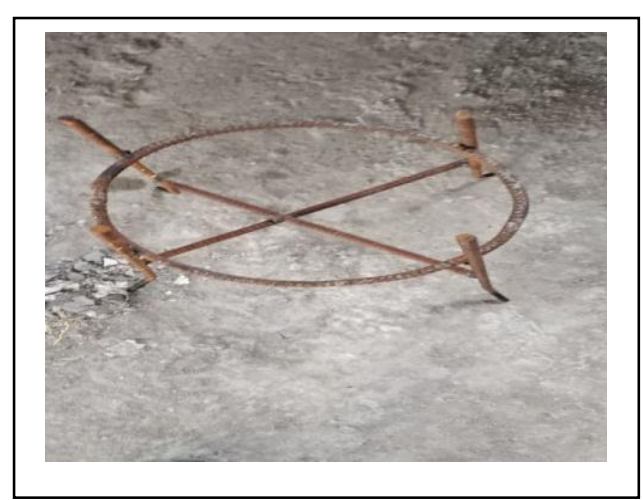

Fig.6.stand

\subsection{Stand for holding plate}

\subsection{Try for collecting of water}

A galvanized sheet tray of $5 / 5 \mathrm{ft}$ made to collect impinged water from the heated plate as shown in figure 7 .

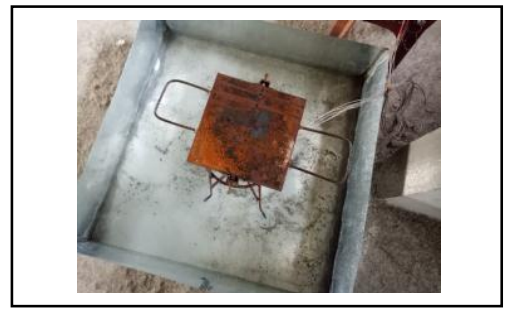

Fig.7.Tray

3.3. Drilling of Square Plate

Figure 8 , shows the drilling of a square plate with hole of $6 \mathrm{~mm}$ diameter and $5 \mathrm{~mm}$ depth in use with center to the plate of equal spacing.

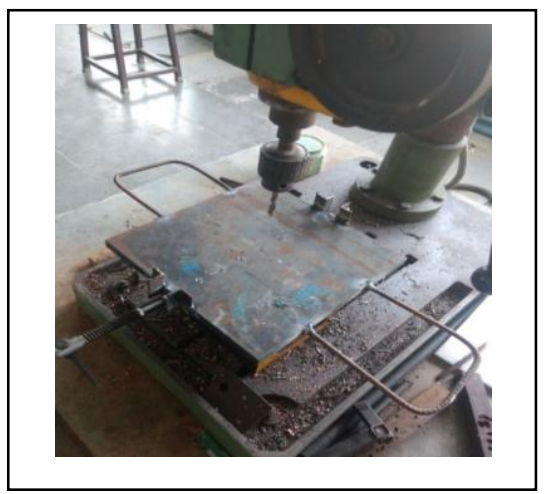

Fig.8. Drilling of mild steel plate

\section{EXPERIMENTAL TESTING}

An AISI 304 square shape Mild steel plate is heated at $700{ }^{0} \mathrm{C}$ and placed on stand for measurement of temperature using thermocouple with application of water at different flow rate $\&$ various height of nozzle. The experimental setup and results are explained below.

\subsection{Experimental setup}

Figure shows experimental setup with attachment of thermocouple for temperature measurement by varying water flow rate at two different heights. The temperature of a square plate is noted down at every $10 \mathrm{sec}$ interval of time.

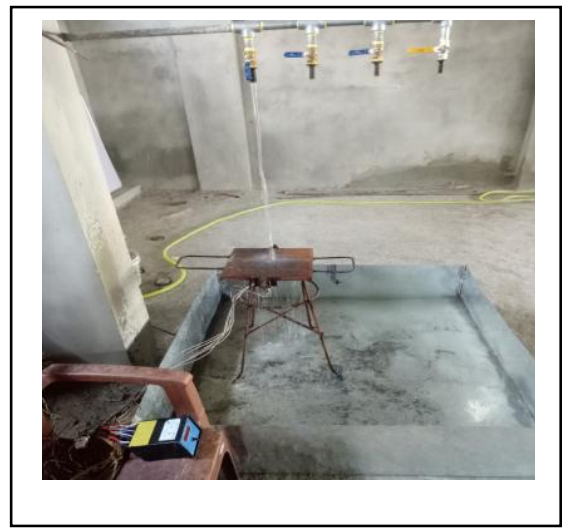

Fig.9. Experimental setup

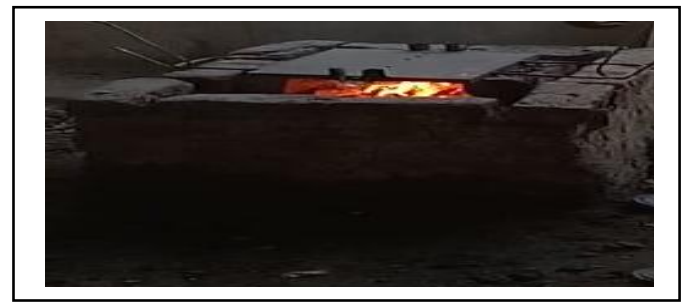

Fig. 9. Heating of plate

A mild steel square plate is heated in a black smithy for temperature of $700^{\circ} \mathrm{C}$ using blower to maintain equal heating as shown in figure.

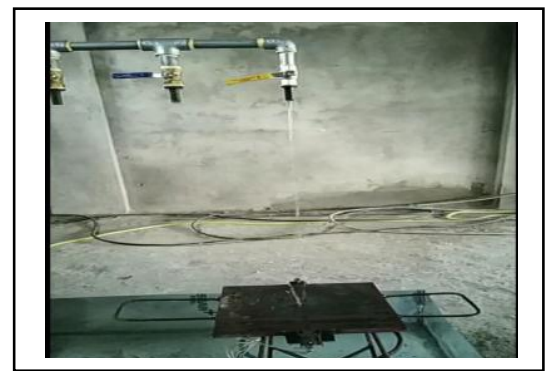

Fig.10. Heating Process

a) Nozzle with diameter of $d=5 \mathrm{~mm} \&$ height $h=$ 3ft

Figure 11 shows cooling of red hot square plate using nozzle with diameter $5 \mathrm{~mm}$ at center of distance $3 \mathrm{ft}$.The cooling of plate is observed with every $10 \mathrm{sec}$ of time interval and it ius noted down till room temperature.

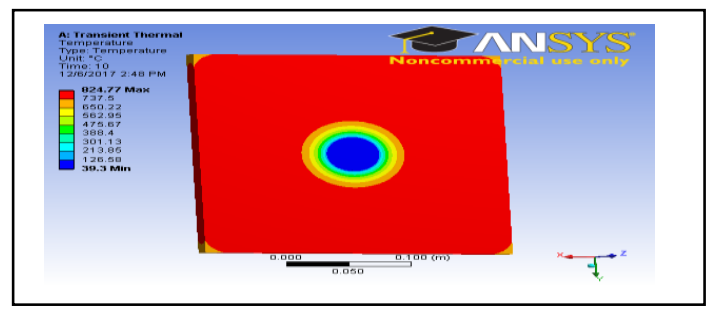

Fig.11.Nozzle at a height $3 \mathrm{ft}$ 


\section{E-ISSN: 2321-9637}

\section{Available online at www.ijrat.org}

The data collected for above experiment tabulated in table 3.1.

\begin{tabular}{|l|l|l|}
\hline SI.No & Time (Sec) & $\begin{array}{l}\text { Temperature } \\
\left({ }^{\mathbf{0}} \mathbf{C}\right)\end{array}$ \\
\hline 1 & 10 & 700 \\
\hline 2 & 20 & 670 \\
\hline 3 & 30 & 600 \\
\hline 4 & 40 & 570 \\
\hline 5 & 50 & 500 \\
\hline 6 & 60 & 450 \\
\hline 7 & 70 & 430 \\
\hline 8 & 80 & 400 \\
\hline 9 & 90 & 360 \\
\hline 10 & 100 & 300 \\
\hline 11 & 110 & 250 \\
\hline 12 & 120 & 200 \\
\hline 13 & 130 & 150 \\
\hline 14 & 140 & 100 \\
\hline 15 & 150 & 60 \\
\hline 16 & 160 & 40 \\
\hline 17 & 170 & 30 \\
\hline
\end{tabular}

Usingthe above tabulated data/reading the graph is plotted as shown in figure 12 .

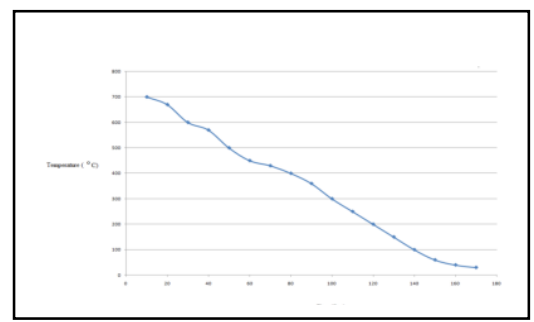

Fig.12. Temperature distribution in a plate $(\mathrm{d}=5 \mathrm{~mm}$, $\mathrm{h}=3 \mathrm{ft}$ )

b) Nozzle with diameter of $d=10 \mathrm{~mm} \&$ height $h=$ 5ft

Figure 13 shows cooling of red hot square plate using nozzle with diameter $10 \mathrm{~mm}$ at center of distance $5 \mathrm{ft}$.The cooling of plate is observed with every $10 \mathrm{sec}$ of time interval and it is noted down till room temperature.

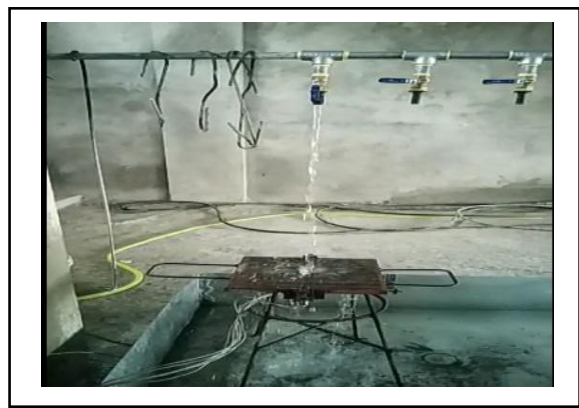

Fig.13.Nozzle at a height $5 \mathrm{ft}$.

The data collected for above experiment tabulated in table 3.2 .
Table 2.Temperature of plate at $h=5 f t$

\begin{tabular}{|l|l|l|}
\hline Sl.No & Time $(\mathbf{S e c})$ & $\begin{array}{l}\text { Temperature } \\
\left({ }^{\mathbf{0}} \mathbf{C}\right)\end{array}$ \\
\hline 1 & 10 & 700 \\
\hline 2 & 20 & 600 \\
\hline 3 & 30 & 530 \\
\hline 4 & 40 & 480 \\
\hline 5 & 50 & 430 \\
\hline 6 & 60 & 380 \\
\hline 7 & 70 & 320 \\
\hline 8 & 80 & 270 \\
\hline 9 & 90 & 200 \\
\hline 10 & 100 & 160 \\
\hline 12 & 110 & 110 \\
\hline 13 & 120 & 60 \\
\hline 14 & 130 & 30 \\
\hline
\end{tabular}

Usingthe above tabulated data/reading the graph is plotted as shown in figure.

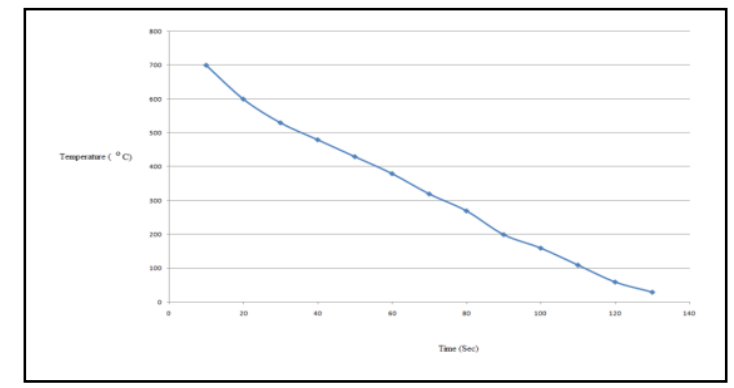

Fig.14.Temperature distribution in a plate $(\mathrm{d}=10 \mathrm{~mm}$, $\mathrm{h}=5 \mathrm{ft}$ )

\section{FINITE ELEMENT ANALYSIS}

Finite element modeling is define here as the analyst choice of material models (constitutive relations and failure criteria), elements (type/shape/order), meshes, constrains, analysis producers, governing matrixes equations and their solution methods, specific pre and post processing options available in a chosen commercial FEA software (ANSYS) for linear stress, buckling and vibration analyses of structures namely space frames, skew plates, shells of revolutions, general shells and built-up structures subjected to thermal and mechanical loads.

\subsection{Geometric Model}

Geometric model of a square plate is created in CATIA V20 with dimension of 1 meter and thickness of 0.02 meter as shown in figure.
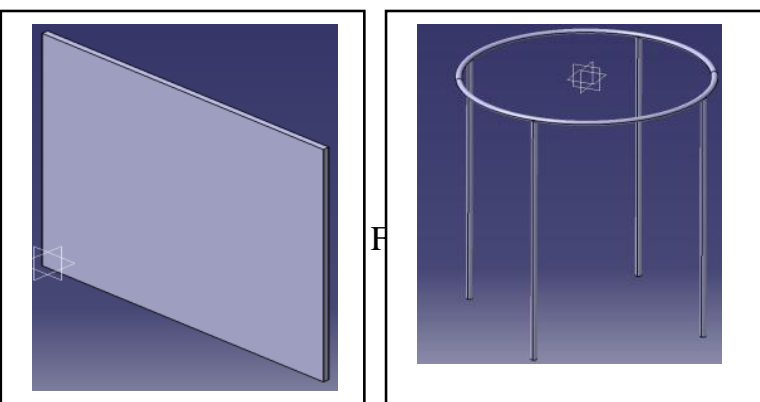

Fig .17. Assemble model of mild steel plate with stand 


\section{E-ISSN: 2321-9637}

\section{Available online at www.ijrat.org}

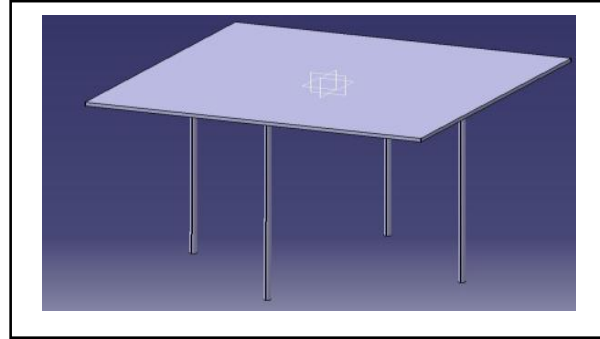

\section{2. . Discretized Model}

Geometric model created in CATIA v5 is imported ANSYS 14.5The imported model is discretize using plane 8 node 82 as shown in figure 18 . Below

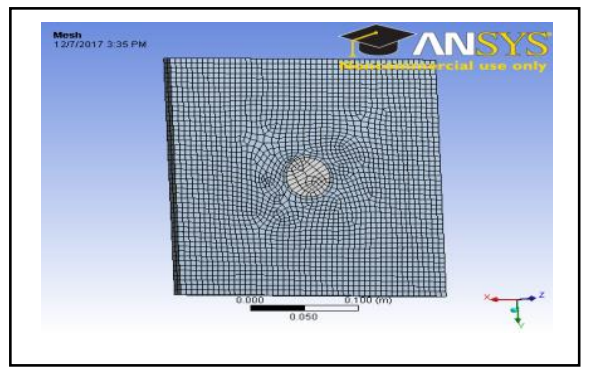

Fig.18.Geometric model

\subsection{Boundary Condition}

A temperature of $700{ }^{\circ} \mathrm{C}$ is applied at the center of the plate and subjected to temperature variation for $10 \mathrm{sec}$ and 20 sec. Figure 19 shows square plate with boundary condition.

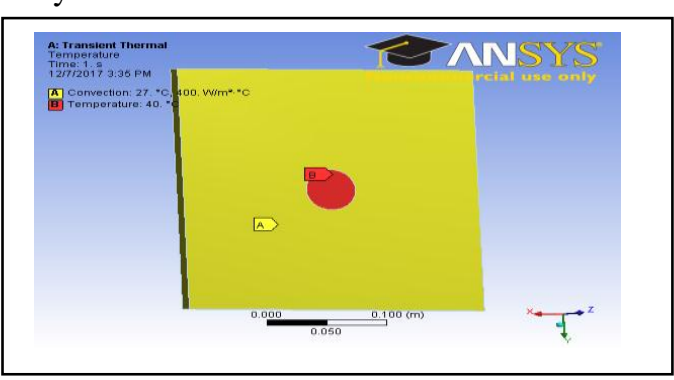

Fig.19.Boundary model

\section{RESULT AND DISCUSSIONS}

Post processing results of finite element model created in ANSYS workbench is discussed below,

\subsection{Temperature Distributions}

Figure 20 Shows the temperature distribution of a plate for 10 seconds subjected to $700{ }^{\circ} \mathrm{C}$. The minimum temperature is observed at the center of the plate with the gradual increasing till the surroundings.

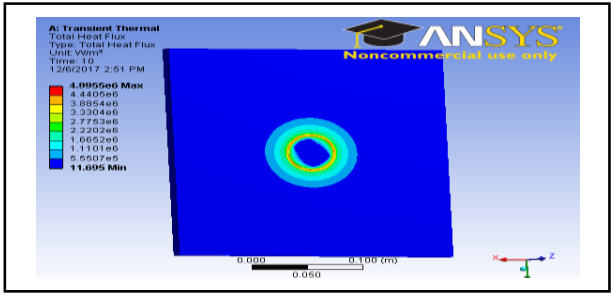

Fig.20.Temperature distribution at time period of 10seconds

Table.3.Temperature distribution of a plate for 10 seconds

\begin{tabular}{|l|l|l|}
\hline S.no & $\begin{array}{l}\text { Minimum } \\
\text { temperature }\left({ }^{0} \mathrm{C}\right)\end{array}$ & $\begin{array}{l}\text { Maximum } \\
\text { temperature }\left({ }^{\circ} \mathrm{C}\right)\end{array}$ \\
\hline 1 & 39.9 & 824 \\
\hline
\end{tabular}

The heat flux distribution of a plate for 10 seconds subjected to $700{ }^{0} \mathrm{C}$. The minimum heat flux is observed at the center of the plate. Figure 21 show the critical heat flux region with red color.

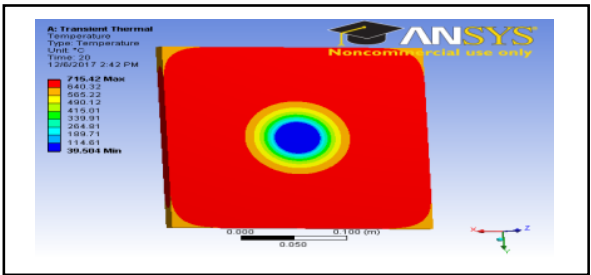

Fig.21.Heat flux at time period of 10 second

Table .4.Heat flux distribution of a plate for 10seconds

\begin{tabular}{|l|l|l|}
\hline S.no & $\begin{array}{l}\text { Minimum } \\
\text { Heat flux } \\
\left({ }^{0} \mathrm{C}\right)\end{array}$ & $\begin{array}{l}\text { Maximum } \\
\text { Heat flux } \\
\left({ }^{0} \mathrm{C}\right)\end{array}$ \\
\hline 1 & 11.695 & 4.440 \\
\hline
\end{tabular}

Figure 22 Shows the temperature distribution of a plate for 20 seconds subjected to $700{ }^{\circ} \mathrm{C}$. The minimum temperature is observed at the center of the plate with the gradual increasing till the surroundings.

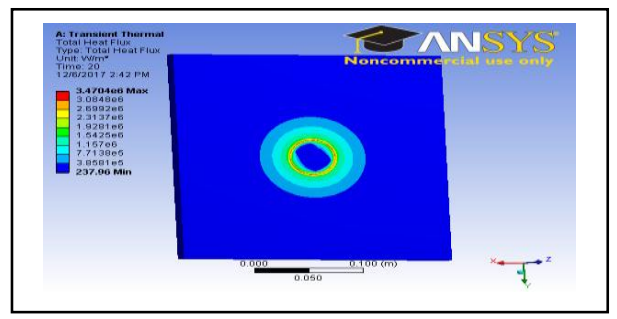

Fig.22.Temperature distribution at Time Period of 20seconds

Table .5.Temperature distribution of a plate for 20 seconds

\begin{tabular}{|l|l|l|}
\hline S.no & $\begin{array}{l}\text { Minimum } \\
\text { temperature }\left({ }^{0} \mathrm{C}\right)\end{array}$ & $\begin{array}{l}\text { Maximum } \\
\text { temperature }\left({ }^{0} \mathrm{C}\right)\end{array}$ \\
\hline 1 & 39.504 & 715.42 \\
\hline
\end{tabular}

The heat flux distribution of a plate for 20 seconds subjected to $700{ }^{0} \mathrm{C}$. The minimum heat flux is observed at the center of the plate. Figure 23 shows the critical heat flux region with red color. 


\section{Available online at www.ijrat.org}

Fig. 23. Heat flux at time period of 20seconds Table.6.Heat flux distribution of a plate for 20 seconds

\begin{tabular}{|l|l|l|}
\hline S.no & $\begin{array}{l}\text { Minimum } \\
\text { Heat flux }\left({ }^{0} \mathrm{C}\right)\end{array}$ & $\begin{array}{l}\text { Maximum } \\
\text { Heat flux } \\
\left({ }^{0} \mathrm{C}\right)\end{array}$ \\
\hline 1 & 237.96 & 3.4704 \\
\hline
\end{tabular}

\section{CONCLUSION}

The objective of this study has been achieved with systematic experimental analysis and numerical modeling for a square plate 1 meter height and width and $20 \mathrm{~mm}$ diameter varying the jet diameter and height of flow. The experimental data has been plotted with recording decreasing temperature in an interval of 10 seconds \& 20 seconds shown graphically. The finite element model is created in ANSYS WORKBENCH and temperature distribution and heat flux variation to show for mild steel plate subjected to temperature of $700^{\circ} \mathrm{C}$ for $10 \& 20$ seconds.

\section{FUTURE SCOPE}

The model presented can be further studied for different combination of material and variant temperatures, jet diameter and validate by experimental data.

\section{REFERENCES}

[1] Ahmet. N. Erslan, Tolga Akis, "Elastoplastic Response of a Long functionally Graded Tube Subjected to Internal Pressure", Turkish Journal of Engineering and Environmental science, Vol.29, 2005, pp. 361-368.

[2] Ahmet. N. Erslan, Tolga Akis, "Plane Strain Analytical Solutions for a Functionally Graded Elastic-Plastic Pressured Tube", International Journal of Pressure vessels and Piping, Vol.83, 2006, pp. 635644.

[3] K. Abrina, H. Naee, F. Sadeghi amd F. Djavanroodi, “ New Analysis for FGM Thick Cylinders under Combined Pressure and Temperature Loading", American Journal of Applied Sciences, Issue 5, Vol. 7, 2008, pp. 852-859.

[4] Naki Tutuncu, "Stresses in Thick-walled FGM cylinders with exponentially varying Properties", Engineering Structures, Vol. 29, 2007, pp. 2032-2035.

[5] S. Schmauder and U. Weber, "Modelling of Functionally Graded Materials by Numerical Homogenization", Archieve of Applied Mechanics, Vol. 71, 2001, pp. 182-192.

[6] Hakan Argeso and Ahmet N. Eraslan, "On the use of Temperature Dependent Physical Properties in Thermomechanical calculations for Solid and Hollow Cylinders", International Journal of Thermal Sciences, Vol. 47, 2008, pp. 136-146.

[7] A. R. Khorshivand and S. M. R. Khalili, "A New Analytical Solution for Deformation and Stresses in Functionally Graded Rotating Cylinder Subjected to Thermal and Mechanical Loads", Proceedings of WSEAS International Conference on Continuum
Mechanics, Fluid Mechanics and Heat \& Mass Transfer, 2010, pp. 201-204.

[8] Ryuzo Watanabe, Toshihiko Nishida and Toshio Hirai, "Present status on Research on Design and Processing of Functionally Graded Materials", METALS and MATERIALS International Journal, Vol. 9, No. 6, 2003, pp. 513 -519.

[9] Victor Birman and Larry. W. Byrd, "Modeling and Analysis of Functionally Graded Materials and Structures", ASME Applied Mechanics Reviews, Vol. 60, 2007, pp. 195-215.

[10]A. Mortensen and S. Suresh, "Functionally Graded Metals and Metal- Ceramic composites", International Materials Review, Vol.40, No.6, 1995, pp. 239-265. 